\title{
Uma nova pedagogia da sexualidade para homens: discursos midiáticos e suas reverberações
}

\author{
I ${ }^{1}$ Cláudia Regina Ribeiro, ${ }^{2}$ Jane Araújo Russo, ${ }^{3}$ Fabíola Rohden I
}

Resumo: Este artigo, norteado pelos conceitos de gênero, masculinidades e sexualidade, analisa os discursos de homens e da revista Men's Health acerca dos aprendizados sobre sexualidade. Foram analisados os editoriais da revista dos anos de 2008 e 2009, as ediçōes desse último ano, e discursos de homens durante entrevistas e grupos focais. Concluímos que a revista apresenta a ideia de uma nova pedagogia da sexualidade para homens, algo novo entre as publicações masculinas, e, com relação aos informantes, que as variáveis classe social, geração e vinculação ao modelo dominante de masculinidade influem fortemente em seus aprendizados sobre sexualidade e na aceitação dessa pedagogia na revista.

> Palavras-chave: gênero; masculinidades; pedagogia da sexualidade; revista Men's Health.

\author{
${ }^{1}$ Doutora em Saúde Coletiva pela \\ Universidade do Estado do Rio \\ de Janeiro. Endereço eletrônico: \\ 13cribeiro@gmail.com \\ ${ }^{2}$ Universidade do Estado do Rio \\ de Janeiro, Instituto de Medicina \\ Social. Endereço eletrônico: jane. \\ russo@gmail.com \\ ${ }^{3}$ Universidade Federal do \\ Rio Grande do Sul. Endereço \\ eletrônico: fabiola.rohden@ \\ gmail.com
}

Recebido em: 26/07/2012 Aprovado em: 16/05/2013 
Lançada no Brasil em maio de 2006, a revista Men's Health tem como leitores projetados homens heterossexuais das classes média e alta urbanas. É classificada como uma revista de serviços, e não de entretenimento, mas mantém o sexo como um tema central, assim como acontece com as revistas tipicamente masculinas. No entanto, percebemos outras nuances na abordagem do tema, as quais podemos chamar de uma nova pedagogia da sexualidade para homens.

Neste artigo, tomamos a ideia de ancoragens da masculinidade hegemônica, ou seja, os aspectos importantes aprendidos desde cedo pelos homens e sobre os quais eles reforçam ou constroem a masculinidade em oposição às mulheres e aos homossexuais. Apontamos a sexualidade como "lugar" privilegiado de ancoragens da masculinidade dominante: a atividade sexual heterossexual, que deve ser mais frequente do que entre as mulheres, a virilidade, a capacidade de penetração durante o ato sexual e a própria penetração. Essas ancoragens são reforçadas por outros aspectos, como a capacidade de prover uma família, a força física, a pouca preocupação com a saúde e a estética, etc.

Nos discursos da revista Men's Health, identificamos também a sexualidade como um aspecto central da masculinidade proposta, mas nos chamaram a atenção as matérias voltadas para o que denominamos "uma nova pedagogia da sexualidade para homens". Esse aspecto torna-se interessante quando identificamos na cultura a ideia de "aptidão e sabedoria inatas masculina para a prática sexual", que dispensariam os homens de uma pedagogia da sexualidade nos termos da revista, diferentemente do que acontece com as mulheres, que há décadas recebem esse tipo de informação de inúmeras revistas femininas. Neste artigo, discutimos a relativização desse aspecto da sexualidade masculina a crença na aptidão natural masculina para o sexo - como ancoragem importante da masculinidade e fronteira construída em relação às mulheres, especificamente, tal como presente nos discursos da revista e de alguns homens entrevistados.

Para a construção dos dados no que diz respeito aos informantes, optamos por grupos focais e entrevistas semiestruturadas. A primeira técnica de abordagem foi escolhida por permitir que em um tempo relativamente curto se possa conhecer crenças, valores, representações sociais, conceitos vigorantes no grupo, zonas de conflito e pontos de vista acerca de um tema específico (FRASER; GONDIM, 2004; LERVOLINO; PELICIONI, 2001; MINAYO, 1999). 
Quanto às entrevistas semiestruturadas, Fraser e Gondim (2004) observam que essa técnica em pesquisa qualitativa é recomendada quando o objetivo é compreender os modos de percepção da realidade, pois possibilita atingir um alto nível de compreensão dos atores sociais. Em ambas as técnicas, está claro que os discursos construídos são textos negociados que envolvem pesquisador/a e entrevistado/a na produção do conhecimento no processo de interação social, a partir de trocas verbais e não verbais.

Realizamos dois eventos de grupos focais que reuniram, respectivamente, três e oito homens não leitores da revista. O primeiro foi realizado com estudantes de um dos cursos de mestrado em Engenharia da UERJ, e o outro, com funcionários de uma empresa de navegação da cidade do Rio de Janeiro. As entrevistas semiestruturadas foram realizadas com 19 homens, leitores e não leitores da revista, e com o seu editor, o jornalista Airton Seligman. Algumas entrevistas foram realizadas face a face, e outras, pela internet, em tempo real. ${ }^{2}$ Todos os participantes assinaram um Termo de Consentimento Livre e Esclarecido e serão identificados por nomes ficticios. ${ }^{3} \mathrm{O}$ editor, pela especificidade de seu cargo, assinou um termo que permitia a divulgação do seu nome. Identificaremos os informantes por faixa etária, classe social a que pertencem, ${ }^{4}$ sexualidade, estado civil, grau de escolaridade e pelo tipo de interação discursiva da qual participou: para entrevistas, usaremos a letra E, e para grupo focal, as letras GF.

Com relação à revista, foram realizadas leituras críticas e fichamentos das edições de 2009 e de 16 editoriais dos anos de 2008 e 2009, ${ }^{5}$ objetivando traçar um panorama do que os homens têm encontrado na publicação, no que diz respeito às matérias sobre sexualidade, sobretudo. Procuramos igualmente identificar marcas discursivas que nos indiquem qual é o padrão de masculinidade, no que diz respeito à sexualidade, que a revista procura construir e vem divulgando como sendo o mais apropriado para os tempos atuais, e o que vem sendo criticado com relação a esse aspecto.

Para a análise dos dados, apropriamo-nos de alguns pressupostos básicos da Análise do Discurso (FOUCAULT, 2007; PINTO, 2002). Isso significa que empreendemos uma investigação sociocultural que procura e interpreta vestígios que permitem a compreensão do contexto imediato, do institucional e do sociocultural mais amplos no interior dos quais se deu o evento comunicacional. "A Análise do Discurso não se interessa tanto pelo que o texto diz e mostra, pois 
não é uma interpretação semântica de conteúdo, mas sim em como e por que o diz e mostra (PINTO, 2002, p. 26).

\section{O universo masculino e suas transformaçôes}

É senso comum afirmarmos que os homens e o universo masculino vêm mudando nas últimas décadas. Essas mudanças vêm em decorrência das transformações nas relações de gênero e de trabalho, impulsionadas, sobretudo, pelos movimentos femininos e LGBT e pelas transformações econômicas e sociais trazidas pelos avanços do capitalismo (NOLASCO, 1993; CONNELL, 1995; 2005; KIMMEL; KAUFMAN, 1995; e outros/as). Não podemos ignorar que a mídia vem se mostrando catalizadora e propagadora dessas mudanças.

Para sustentar a discussão a respeito desses tópicos e promover a análise em questão, partimos de algumas referências fundamentais, dentre as quais se destaca o próprio conceito de gênero. Sem adentrar no amplo debate em seu entorno, salientamos a sua importância ao distinguir os imperativos sociais, culturais e históricos da ideia de determinação biológica implícita no uso dos termos como sexo e diferença sexual (SCOTT, 1995). Assume-se uma perspectiva em que gênero se refere, portanto, "às qualidades fundamentalmente sociais das distinções baseadas no sexo", que se constroem de forma relacional e que variam em cada momento histórico, sociedade e cultura (1995). As relações de gênero não dizem respeito somente àquelas entre mulheres e homens, mas “incluem relações entre os homens, relações de dominação, marginalização e cumplicidade" (CONNELL, 1995). São aspecto essencial para refletirmos sobre os discursos de nossos informantes e da revista Men's Health.

Tomando a definiçãao de Jeffrey Weeks (1999), que se apoia nas concepções de Foucault (1997), a sexualidade é considerada o conjunto de crenças e comportamentos que se relacionam com "o corpo e seus prazeres". Sendo construções socioculturais e não inatas ou universais, as concepções acerca da sexualidade se alteram, dependendo do lugar e do momento histórico, estando submetidas às formas de atuação do poder em cada sociedade. Foucault (1985) afirma que o termo "sexualidade" surgiu no início do século XIX, possuindo, portanto, uma historicidade e relacionando-se com outros acontecimentos, como a consolidação do capitalismo. Na sociedade que se instala, dar sentido às práticas 
sexuais e colocá-las em discurso são estratégias do poder disciplinar que toma a sexualidade como lugar privilegiado do seu exercício.

A partir da construção da ideia e do termo, a sexualidade passa a ser uma experiência, algo que pode ser colocado em discurso e problematizado. Falar de sexualidade não significa falar de desejo ou de libido, mas das

práticas pelas quais os indivíduos foram levados a prestar atenção a eles próprios, a se decifrar, a se reconhecer e se confessar como sujeitos de desejo, estabelecendo de si para consigo uma certa relação que lhes permite descobrir no desejo, a verdade de seu ser, seja ele natural ou decaído.

Isso diz respeito às "mudanças no modo pelo qual os indivíduos são levados a dar sentido à sua conduta, seus deveres, prazeres, sentimentos, sensações e sonhos" (FOUCAULT, 1985). Tratando-se de poder e sexualidade, Foucault nos lembra que, diferente do que se possa pensar, a "sexualidade não é fundamentalmente aquilo de que o poder tem medo; mas que ela é, sem dúvida e antes de tudo, aquilo através de que ele se exerce" (1993).

É importante enfatizar que nossas construções acerca do gênero se dão sobre corpos femininos e masculinos (CONNELL, 1995), e que elas estão entrelaçadas às do sexo e da sexualidade, aparecendo como tal nos discursos da revista e dos participantes da pesquisa. Usamos aqui o termo "sexo" para nos referirmos às práticas e atividades sexuais que podem ser aprendidas como qualquer outra atividade humana (HEILBORN, 2006).

No que diz respeito mais especificamente aos homens, foi nos anos 70 e 80 que estudiosos/as norte-americanos/as e ingleses/as das ciências sociais começaram a se debruçar de forma sistemática sobre as questôes do gênero masculino, construindo com suas pesquisas o que passou a ser chamado de Men's Studies. Pode-se dizer que esses estudos são um desdobramento dos movimentos feministas e homossexuais iniciados nas décadas de 60 e 70, respectivamente. Tendo como proposta problematizar o androcentrismo e a dominação masculina, tais movimentos acabaram por trazer o universo masculino para a arena das discussóes de gênero (BADINTER, 2010; HEILBORN; CARRARA, 1998; ALMEIDA, 2000).

Todos esses questionamentos "balançam o sólido edifício" da masculinidade, refletindo-se na chamada "crise do masculino", que começa a aflorar (KIMMEL; KAUFMAN, 1995; HEILBORN; CARRARA, 1998; BADINTER, 2010; ALMEIDA, 2000; CONNELL; KIMMEL; HEARN, 2005). É essa crise 
que provoca os homens a também se tornarem atores das mudanças, inclusive organizando-se em grupos para discutir novos rumos para o gênero masculino, propor mudanças no que diz respeito a aspectos como a vida doméstica, ou mesmo para se apoiarem mutuamente (NOLASCO, 1993; HEILBORN; CARRARA, 1998; KIMMEL; KAUFMAN, 1995). Assim, as especificidades das diferentes masculinidades estão agora sendo reconhecidas, e suas origens, estruturas e dinâmicas, investigadas. É desse cenário do qual partimos para falar de mudanças no universo masculino e de um "novo homem".

Parece ser consenso entre os/as estudiosos/as de gênero, em especial dos Men's Studies, que construir-se como homem é um projeto permanente e requer muitos cuidados. Para Raewyn Connell ${ }^{6}$ (1995) e Miguel Vale de Almeida (2000), a masculinidade é um projeto perseguido durante muitos anos e sujeito a muitas voltas e reviravoltas, envolvendo encontros com instituiçôes e forças culturais como a comunicação de massa, e que pode ser assumido ou refutado por homens e mulheres. Ser masculino tem relação com requisitos que se espalham "por todos os níveis do social, desde a família ao trabalho, do prestígio ao status, da classe social à idade, passando pela linguagem verbal e gestual; enfim, a lista seria tão vasta quanto à totalidade do social" (ALMEIDA, 2000).

Apesar de também estar inscrito no corpo, ser homem é algo muito mais complexo: é portar "um conjunto de atributos morais de comportamento, socialmente sancionados e constantemente reavaliados, negociados, relembrados. Em suma, em constante processo de construção" (ALMEIDA, 2000). Além disso, como afirma Michael Kimmel (1998), a masculinidade não é uma essência eterna, mas varia de cultura para cultura, de geração para geração dentro de uma mesma cultura, e mesmo ao longo da vida de qualquer homem individualmente.

Existem, portanto, muitas formas de ser homem e masculino dentro de uma mesma sociedade em um mesmo período histórico. No entanto, cada sociedade em cada momento constrói um modelo de masculinidade que se constitui como um padrão cultural ideal pelo qual todos os homens se medem (KIMMEL, 1998). Esse modelo dominante, ou hegemônico, é construído a partir de narrativas presentes na cultura que informam como os homens devem ser, como se comportar, do que devem gostar e do que se aproximar ou se afastar, tendo como referência as mulheres. A existência de um modelo dominante pressupõe a existência de outras formas de ser masculino que dele destoam e que, na lógica da 
construção do gênero masculino e do modelo de masculinidade, têm como uma das funções a de ratificar, por oposição, o modelo dominante. Se ser heterossexual é o pressuposto primeiro da masculinidade hegemônica, ser homossexual é o que caracteriza primeiramente a masculinidade subalterna. Mas a definição de subalternidade se estende a todos os que não correspondem ao padrão.

Podemos dizer, assim, que as normas de gênero são fluidas e estão submetidas, também, às práticas e necessidades do cotidiano, sendo colocadas em jogo, ou de lado, sempre que se faz necessário, incluindo-se nesta dinâmica os modelos hegemônico e subalterno de masculinidade. Nos últimos anos do século XX, despontaram no cenário do ocidente duas novas configurações de masculinidade: o metrossexual e o "novo homem". Esses dois modelos foram insistentemente anunciados na mídia como sendo padrões de masculinidade mais próprios aos tempos atuais. É importante referir também que a mídia é um elemento fundamental da sociedade de consumo e tem um papel importante na propagação desses novos modelos de masculinidade.

O "novo homem", modelo que nos interessa neste trabalho, da forma como foi configurado pela mídia, é uma tentativa de ordenar alguns padrôes da masculinidade após todos os abalos provocados pelos movimentos sociais das últimas décadas. Esse modelo, organizado em suas características, gostos e desejos, constitui uma forma de os homens se encaixarem na modernidade. Ser um "novo homem" significa rejeitar o "machismo" como marca fundamental da masculinidade tradicional ${ }^{9}$. Pressupõe, basicamente, investimentos estéticos e na saúde, a realização de tarefas até então tomadas como obrigações femininas ou próprias às mulheres, valorização do contato e cuidado com os/as filhos/as, respeito e valorização da mulher em suas buscas profissionais, refutação do valor da virgindade feminina, entre outros aspectos.

Tal modelo está presente nos discursos da revista, atrelado aos cuidados corporais e à conformação de novos gostos e consumos, principalmente. Esteve presente igualmente nas falas de leitores e não leitores da revista, independente da classe social, mostrando que, apesar de ser um fenômeno claramente das classes médias, espraia-se pela sociedade, sobretudo por ser também fortemente anunciado pela mídia. Esses novos modelos só têm lugar num mundo em que as relaçôes entre os gêneros feminino e masculino estão em transformação, e também, como refere Sean Nixon (2003), num mundo em que as relações 
entre os próprios homens estão se transformando, pois é principalmente aos seus pares que a todo o momento os homens precisam provar sua masculinidade, sendo eles os que darão, ou não, o aval para as mudanças. Percebê-las significa compreender que também estão em marcha transformações no que os próprios homens acreditam ser próprio do masculino.

\section{Uma nova pedagogia da sexualidade para homens}

Na revista Men's Health, a sexualidade e o sexo são temas centrais e têm lugar de forma explícita nas seções: "Mixer: sexo" e "Boletim: sexo". Aparecem de forma implícita em diversas outras seções, como quando a conquista amorosa/sexual é arrolada como bom motivo para se exercitar, comer melhor, ir ao médico ou se arrumar, por exemplo, ou quando as matérias que nada têm a ver com sexo são ilustradas por fotos de mulheres em poses e roupas sensuais. Nas capas, há sempre a foto de uma mulher nua ou vestindo roupas de banho ou lingerie, que ilustra a chamada da seção "Sexo".

As fotos, mais do que indicam o teor da matéria, sinalizam que se trata de uma revista para o homem heterossexual, uma vez que, como nos lembra Olivarria (1999), o desejo por uma mulher está no centro da sexualidade masculina heterossexual. Essa informação é reforçada em algumas edições que trazem, na foto central das capas, um casal heterossexual. Nessas matérias, o corpo e a psicologia femininos (este último aspecto fica em segundo plano) são representados como "misteriosos" e sujeitos às variações hormonais, destacando as ciências médicas como fontes principais dos ensinamentos sobre sexualidade.

Matérias sobre sexo em revistas tradicionais masculinas não são, de forma alguma, algo inovador. Mas nos chamou a atenção o tratamento dado ao que estamos chamando de "uma nova pedagogia da sexualidade para homens". Tratase de discursos que têm o objetivo de esclarecer e ensinar sobre sexo e sexualidade e que diferem do que os informantes com mais de 40 anos nos afirmaram terem sido suas fontes de informação: "folhas" com imagens de posições sexuais, revistas suecas e filmes pornográficos. Essa abordagem pedagógica, embora alguns sujeitos afirmem já tê-la visto na revista Playboy, não é comum nas publicações tradicionais para o público masculino.

Referimo-nos a ensinamentos como os da seção "Mixer: sexo", que no mês de outubro de 2009 trouxe como tema algumas formas de utilização do vibrador 
(apetrecho erótico em forma de pênis) como estratégia para melhorar o sexo. A matéria trouxe o seguinte texto: "No começo da transa, use o acessório em velocidade baixa para acariciar o corpo dela [...]. [P] ara chegar ao sexo anal, o vibrador pode facilitar o trajeto. Com um modelo pequeno, sinta a reação da parceira e comece a brincadeira”. Em fevereiro, sobre atualização das táticas sexuais, recomenda:

[...] recuar quando ela estiver quase lá pode potencializar o orgasmo dela [...]. Peça para ela avisar quando a hora estiver chegando e pare por alguns minutos para beijá-la. Faça isso várias vezes até levá-la ao delírio. Não se preocupe em estragar o momento - são necessários entre cinco e dez minutos para o clima esfriar.

Não se trata somente de uma pedagogia sobre o corpo e o prazer feminino. Os homens também são contemplados, como na seção de julho, que tratava da variação do desejo sexual ao longo do dia a partir das $7 \mathrm{~h}$ : "8h o corpo está com seu pico de testosterona, hormônio que aumenta a libido e potencializa a ereção. Essa é a melhor hora para o sexo. Portanto, transe".

Essa pedagogia é apresentada ainda na seção "Boletim: sexo", em matérias ao longo da revista que podem variar em número, entre uma ou duas, e, eventualmente, como na edição de abril, só estar presente na seção "Mixer". Também a encontramos nas seçôes "Pergunte à vizinha", "Gil, o garçom" e nas duas seções de cartas dos/as leitores/as, as quais trazem perguntas e respostas sobre sexo e outros temas. As matérias maiores estão espalhadas pela revista e trazem abordagens diversas sobre sexo: como lidar com as "neuras" sexuais das mulheres; como identificar o grau do desejo sexual de uma mulher pela lingerie que ela usa; como perceber se ela está "a fim” pelo modo de sentar em um bar; ou como melhorar a performance sexual, entre tantos outros temas que trazem respostas às dúvidas dos homens e que pretendem ajudá-los a melhor compreender as mulheres e a si mesmos, visando a uma vida sexual mais intensa e prazerosa, como esclarece o editor:

A gente dá essas dicas para que o homem dê prazer a sua parceira e, portanto, tenha prazer também. O que que a gente quer dele? Que ele tenha prazer. Nós somos amigos do nosso leitor. A gente quer que ele tenha o máximo de prazer. Como que a gente vai levá-lo ao máximo de prazer? Dando prazer à sua parceira. Pra que ela dê pra você.

Chamamos a atenção para outro aspecto sobre a pedagogia da sexualidade nas revistas masculinas e na Men's Health em especial. Segundo Jair Ramos, as revistas masculinas tradicionais como Playboy e Sexy "colocam o leitor na condição de sujeito de desejo diante de corpos femininos", diferente do que 
acontece com as leitoras diante das revistas tradicionais para mulheres, que devem "se enxergar e agir sobre si, tornando o seu próprio corpo objeto de uma intervenção" (RAMOS, 2011) a partir da exposição dos corpos femininos, de enquetes e recomendações. No caso das matérias sobre sexualidade na Men's Health, os corpos das leitoras estão assujeitados aos homens, que devem esmiuçálos e compreendê-los para agir de forma a dar e a obter mais prazer deles. Um aspecto novo entre as revistas masculinas.

Essa resposta nos mostra que as matérias, mais do que orientar os homens sobre como agradar sexualmente as mulheres, têm o propósito de orientá-los sobre como potencializar o seu próprio prazer.

Trazemos agora as impressões de alguns informantes sobre aprendizados sexuais e sobre a possibilidade de aprendizado da sexualidade em uma revista, como vem sendo ofertado às mulheres há tantos anos, além de outras nuances sobre esse tema e sobre a própria ideia de masculinidade flagrantes nos discursos. Embora tenhamos realizado entrevistas com homens homossexuais e bissexuais, privilegiamos os discursos dos heterossexuais, pois é a eles que a revista se dirige formalmente.

Entre esses homens surgiram, grosso modo, duas formas distintas de referência ao tema: o aprendizado a partir de leituras (revistas e sites) e a partir da experiência. As duas possibilidades não se excluem mutuamente, podendo um mesmo sujeito afirmar que aprendeu ou vem aprimorando sua performance sexual através das duas formas. Para nos ajudar metodologicamente na análise e apontar as marcas principais encontradas nos discursos, construímos três modelos classificatórios de discursos a partir de marcas recorrentes: (1) esse aprendizado foi e pode ser adquirido com leituras e com a prática, conferindo valor às duas formas; (2) desvalorização do aprendizado pela leitura e dos próprios leitores, imputando muito valor ao aprendizado pela prática; (3) e não desvalorização da leitura (e dos leitores), mas também não a reconhecendo como vantajosa.

Percebemos que a construção desses discursos dependeu sobremaneira das variáveis classe social e geração. De forma especial, foram marcados pelo alinhamento com o padrão hegemônico de masculinidade presente em nossa cultura ou pela flexibilização com relação a esse modelo. Mas é importante dizer que os discursos não são monolíticos e muitas vezes apresentam contradições e marcas que podemos identificar como pertencentes a dois pontos de vista distintos. Os discursos que apresentam mais fortemente as duas primeiras marcas, 
ou pertencem aos dois primeiros grupos, se mostraram muito ricos, e, por isso, serão analisados mais detidamente.

Em relação aos discursos que trazem as marcas do primeiro grupo, independentemente dos sujeitos serem leitores ou não da Men's Health, os mais jovens demostraram maior facilidade em admitir que desconhecem os meandros da prática sexual e, por isso, buscam informação sobre o tema, assim como podem fazer as mulheres. Destacamos os discursos de Hélio, Anderson, Edgar, Davi e Wilian, todos na faixa entre 22 e 26 anos. Sendo mais jovens, eles, em tese, têm menos experiência sexual, o que justificaria a busca por informações, mas não a forma tranquila como assumiram essa busca, se compararmos seus discursos aos dos informantes que se posicionaram de forma muito crítica em relação a essa possibilidade de aprendizado da sexualidade. Por isso, acreditamos que os discursos desses jovens revelam uma flexibilização da masculinidade dominante nesse aspecto.

O segundo grupo foi formado por um número pequeno de entrevistados, dentre os quais destacamos Fernando e Rob (GF), bastante contundentes em seu alinhamento com posições tradicionais da masculinidade, demostrando pouca flexibilidade com relação a ela. Reconhecemos que, nos discursos desses dois sujeitos, a afirmação e a valorização do aprendizado a partir da prática eram trazidas como forma de agregar valor à sua masculinidade, uma vez que esse tipo de aprendizado revelaria competência, vivência sexual e distanciamento com relação às mulheres.

Outros homens construíram discursos que seriam arrolados mais facilmente no terceiro grupo, como Augusto, Tony, Rodrigo, Célio e Lucas. Estes, apesar de se colocarem como aprendizes através da prática, não desqualificaram de todo os possíveis aprendizados através da leitura da Men's Health ou de outras publicações que, diferentemente do "seu tempo", podem ser encontradas agora nas bancas. A geração é uma marca importante desse grupo, pois alguns desses homens dispuseram apenas da prática e das conversas com amigos para aprender sobre sexualidade e sexo no início da sua vida sexual, como são os casos de Eraldo e Benito. Alguns se referiram a cartilhas e "folhas", consideradas relevantes para seus aprendizados sexuais, mas nada que fosse parecido com uma pedagogia da sexualidade como temos na Men's Health. Alguns trouxeram ainda um aspecto interessante: a crença de que o convívio com a parceira é a forma mais adequada para 
o aprendizado e obtenção do prazer sexual. Ou seja, os que vêm-se beneficiando de uma pedagogia através de leituras são os jovens que não desejam manter um vínculo afetivo com a parceira sexual. Por isso, associam o aprendizado a partir da leitura à juventude e aos relacionamentos fugazes próprios dos novos tempos.

\section{Nossos interlocutores e seus aprendizados sexuais}

Começamos a análise a partir dos homens que construíram discursos emblemáticos do segundo e terceiro modelos propostos. O discurso de Fernando (E), 30 anos, assinante da revista, solteiro, com nível médio de escolaridade e pertencente às camadas populares, é bastante alinhado com a publicação no que diz respeito aos cuidados com o corpo, alimentação e saúde, mas quando se referiu às matérias sobre sexualidade se mostrou refratário à possibilidade de aprender com elas. Podemos incluí-lo, portanto, entre os homens que construíram discursos alinhados com o segundo modelo, ou seja, um alguém que aprende sexo na prática. Algumas contradições em seu discurso, entretanto, nos permitem inferir que a ênfase atribuída ao aprendizado pela prática e as críticas que constrói contra quem aprende com leituras têm a função de maximizar sua masculinidade e compensar desvantagens sociais, econômicas e de formação.

Afirma, por exemplo, que lê toda a revista:

Leio das cartas até a última página que são as brincadeiras que eles fazem às vezes. Eu leio a revista toda. [Fernando]

Ao citar uma das matérias que considera interessantes, diz:

Tem umas matérias dessas agora esses dias. Tipo: o que você tem que fazer, o que não pode fazer desde o momento que você sai com ela, que você leva ela pra sua casa, não pode ter toalha, cueca, essas coisas, até a forma de você começar a acariciar ela pra deixar ela no ponto, né? [Fernando]

Ao mesmo tempo, afirma não usar essas dicas com a namorada:

Pra certas pessoas pode ser útil, né? Pra mim é, mas eu não leio muito porque, vamos dizer assim, tem umas... porra, eu tenho trinta anos, entendeu? Não é o meu... não costumo muito, como vou dizer, assim...não costumo muito.. agora me deu branco... mas eu sempre leio. Eu leio tudo, leio [...]. Não é questão de faixa etária, é mais de vivência. Não tem nada que eu já não saiba, entendeu? É mais ou menos isso. Mas é legal... mas nada é novo pra mim. Quer dizer, para um garoto de 16 anos, 17 anos, que tá começando sua vida sexual agora, é bem mais válido pra ele do que pra mim, entendeu? Porque depende da vivência da pessoa, né? Depende da vivência mesmo. Tem cara de 30 anos aqui [na academia] que tem mentalidade de 15, entendeu? Ainda mais, pô, zona sul, tem muita garotada boba, tem muita gente boba, bobinha. [Fernando] 
Foi curioso notar o desconforto do informante quando questionado sobre o tema, perceptível na impossibilidade de encontrar palavras para dizer o que achava das matérias. A valorização da prática e a dificuldade de falar sobre o tema nos remete à afirmação de alguns/as autores/as sobre a socialização dos rapazes das camadas populares no que diz respeito à sexualidade. Duas das marcas dessa socialização são a valorização da agressividade e da indisciplina sexual, e a ideia de que sexo não é algo que se discute, mas que se aprende com a vivência e a prática (HEILBORN; GOUVEIA, 1999; OLIVARRIA, 1999). O informante Tony (E), 45 anos, casado, com nível superior, de classe média e não leitor da revista, constrói discursos que corroboram a opinião de Fernando quanto à faixa etária dos leitores dessas matérias. Mas seu discurso pode ser arrolado entre os do terceiro grupo, pois não desqualifica os leitores e os aprendizados trazidos pela leitura. Para ele, que revela já ter lido e comprado a revista duas vezes para se informar sobre exercícios físicos, mas que leu algumas matérias sobre sexualidade por curiosidade, afirma que o homem que as lê se define

não pela idade, é mais experiência, né... pouca experiência, que tem algum problema, dúvida, acho interessante. [Tony]

Afirmou, ainda, que procurou informações sobre o tema quando iniciou sua vida sexual, mas não conferiu grande importância a esses aprendizados:

Ah, tinha a conversa com os amigos, revistas, livros, e o resto foi naturalmente. Eu cheguei a ler alguma coisa num relatório (Hite, Kinsey ou Masters\&Johnsons) porque eu tinha uma tia que era psicóloga. E revista, às vezes lia, acho que devia ser a Playboy, esse negócio assim [...]. [L]ia de curiosidade, mas acho que ajuda sim... [Tony]

O que diferencia também o discurso de Tony do de Fernando é que o primeiro foi bem menos explícito na construção de si como um homem experiente, limitando-se a dizer que "nessa altura do campeonato [esse tipo de matéria] já não ajudava tanto".

Está claro então que Fernando não foi o único homem que afirmou ter aprendido a fazer sexo praticando. Os homens com mais de 40 anos disseram o mesmo. O informante Eraldo (E), 45 anos, casado, com nível médio, de classe popular e não leitor, vivenciou sua iniciação sexual de forma bem típica e de acordo com a sua geração, com prostitutas, afirmando que toda a aprendizagem se deu com a prática e a experiência.

É no dia a dia mesmo, na prática que você vai se descobrindo. Vai aprendendo uma coisinha aqui, uma coisinha ali, um tiquinho aqui, um pouquinho lá, umas prelimi- 
nares, não sei o quê [...] Agora, ler como é que faz, não. [...] Não dá pra pegar a revista, ler... é interessante porque muitas novidades, muitas posições, muitos modelos que as pessoas não conhecem, porque realmente você nunca sabe tudo. [Eraldo]

Mauro (E), 52 anos, casado, com nível superior, de classe média e não leitor, afirma que também frequentava a "zona" por curiosidade, mas que a primeira experiência sexual foi com uma namorada, pois nunca teve coragem de fazer sexo com uma prostituta. No entanto, também afirmou ter comprado uma ou duas edições da Men's Health, uma que trazia uma matéria sobre como perder a barriga e outra com dicas de sexualidade sobre como levar uma mulher ao clímax rapidamente. Segundo ele,

era só curiosidade para saber o que estava falando na revista... os sete ou dez meios de fazer a mulher se excitar ou ter prazer com mais facilidade, não sei [...]. Gostei, achei interessante. Informação, né? A tua mulher também cresce, né? Não sendo mais uma menina, então, você também tem que ter qualidade na relação, né? [Mauro]

Esses homens com mais de 40 anos que afirmaram ter aprendido sobretudo com a prática revelaram aspectos curiosos sobre seus aprendizados, inclusive através de certas mídias. Benito (E) - 48 anos, casado, com nível superior, de classe média e não leitor -, Célio (E) - 50 anos, casado, com nível superior, de classe média e não leitor - e Eraldo disseram o seguinte:

Não tinha nada naquela época. As fotos eram até pudicas, né? Só apareciam seios mesmo. Se você quisesse ver alguma coisa mais abrangente eram os filmes suecos que você via. Eu tinha primos mais velhos e às vezes eles conseguiam até projetores mesmo. A gente viu uma vez ou outra escondido [...]. Cinema era pornochanchada... se bem que aquilo deixava a gente excitado quando colocava [...]. Eu tinha também uns primos que tinham o pai ginecologista e explicava as coisas a eles e aí a gente conversava... [Benito]

No meu tempo, tinha uma revista colorida que era importada e o jornaleiro te dava, mas ninguém podia dizer que ele vendeu, eram posiçôes. Às vezes só o pai que tinha e guardava lá, nem a mãe sabia, aí você roubava... era importada, colorida, sueca, show de bola... posiçōes. [Célio]

Quando eu era mais novo, eu tinha uma folha, um cara me conseguiu uma folha com 10, 15 posições. É, várias posições. Mas nada escrito. Eram só os desenhos dos bonequinhos só. Eu tive isso guardado muito tempo ainda. [Eraldo]

Então, se compararmos os discursos de Fernando aos desses informantes, com idade superior a 40 anos, perceberemos que eles também conferem valor ao aprendizado com a prática. Ainda assim, os discursos de Fernando se distanciam de 
todo o corpus construído durante a pesquisa, uma vez que nenhum homem, mesmo

os que não se interessam por matérias sobre sexualidade, afirmou que "não tem nada que eu já não saiba” acerca das matérias da revista, como fez o informante.

É muito interessante ainda sua colocação de que os rapazes mais jovens e moradores da zona sul do Rio de Janeiro, os que pertencem às classes médias e altas, são os que mais necessitariam desses ensinamentos e se beneficiariam com a leitura dessas matérias. Rapazes que, diferente dele, não aprendem com a prática, mas com leituras e discussões. Para ele, a classe e a faixa etária juntas seriam elementos significativos na construção de rapazes mais ou menos experientes sexualmente, ou mais ou menos "bobinhos", como preferiu dizer. Ele se coloca explicitamente fora do grupo dos bobinhos ao apontar sua faixa etária, sua experiência e, de forma menos evidente, sua classe social como elementos fundamentais no que diz respeito aos conhecimentos e qualidades da sua prática sexual. Parece-nos, portanto, que Fernando compensa o seu pertencimento de classe através da sua experiência como homem. Ela transforma o que antes seria inferioridade em superioridade. Ou seja, ele é superior sexualmente porque sua classe permitiu que ele assim se construísse, conseguindo transformar sua condição social em vantagem.

O outro informante enfático ao desvalorizar o aprendizado com leituras foi Rob - 32 anos, solteiro, com mestrado, de classe média e não leitor da Men's Health -, cujo discurso foi construído no evento de grupo focal da UERJ, aspecto que precisa ser considerado. Ao se referir a uma reportagem da revista, afirmou o seguinte:

O cara que vai ler a reportagem 'Doze jeitos de acabar na cama com ela', ou é para moleque novo... Sabe, novo, sei lá... [Rob]

A frase curta é parte de uma longa fala em que o informante desqualifica o leitor da revista, afirmando que não os admira pois são homens vaidosos, metrossexuais ou gays. E é importante dizer que essa afirmação foi feita depois que seu colega de curso, Luiz - 42 anos, casado, com mestrado, de classe média e não leitor -, havia dito já ter consultado sites e revistas para saber mais sobre sexualidade e sobre como tratar uma mulher. Depois das colocações de Rob, Luiz retomou o assunto e afirmou que não compraria a revista Men's Health:

Não é o meu perfil esse tipo de leitura. Eu gosto de coisas pontuais. Se tiver na chamada da revista uma coisa pontual que interessa, eu vou ler. Mas eu não vou chegar na banca e comprar toda semana. [Luiz] 
De toda forma, Luiz construiu discursos representativos do primeiro modelo classificatório.

Diferente de Fernando, o informante Rob, mestre em Engenharia, estava realizando o seu segundo curso de Mestrado. Profissionalmente, atua como policial vinculado a uma unidade especializada em realizar intervençôes e enfrentamentos de alto risco. Isso nos leva a crer que os discursos atravessados pela ideia de desprezo que construiu sobre os homens que aprendem sobre sexualidade lendo matérias da Men's Health têm relação com a redundante afirmação de sua masculinidade (aspecto também presente nos discursos de Fernando), e não com a variável classe social, que acreditamos ter levado Fernando, pertencente às camadas populares, a construir discursos similares. Acreditamos que o discurso sobre o aprendizado da sexualidade se agrega a outros sobre a violência cotidiana de sua profissão e sua prática de esportes radicais, ao uso excessivo de bebidas alcoólicas e ao seu pouco cuidado com a saúde, construindo para si uma hipermasculinidade, marca central de seu discurso.

Para concluir o quadro que buscamos montar sobre os discursos que sustentam a resistência aos aprendizados de sexualidade através de leituras, trazemos a fala do leitor Lucas (E), 33 anos, solteiro, com nível superior, de classe média. Assim como os demais leitores da Men's Health entrevistados, Lucas informou-nos que estas não são matérias que o interessariam em primeiro lugar na revista, mas que "é legal, muito bom" ler sobre esses temas. Seu discurso disse respeito tanto à relação entre a masculinidade e a possibilidade de leitura dessas matérias quanto sobre si mesmo como leitor delas:

A mulher lê essas revistas. Agora, uma revista voltada para homem que falava disso não tinha. Então, essa revista veio pra gente para quebrar esse tabu de falar de sexualidade pro homem que tem esse preconceito de chegar e pegar e ler. Então quando ele pega uma revista que não é voltada só pra sexualidade, é pra outra coisa, ele pega e lê, faz teste [...]. Muita gente acha isso, o cara: 'Ah, eu sei tudo, eu faço tudo, eu sou bom'. O mundo é muito machista até hoje [...] Agora, uma revista só de sexualidade voltada para o homem, eu acho que a revista vai encalhar...um homem chegar numa banca de jornal "Ah, me vê uma Capricho masculina?". O cara vai olhar "Hum...”. [Lucas]

Sobre sua relação com a leitura dessas matérias, diz o seguinte:

Eu pego a revista e leio a revista inteira, mas eu leio porque vem junto da revista. Porque se eu fosse pra banca comprar, eu não compraria [...] Eu não teria vergonha, eu sou cabeça aberta, comigo não tem essa, não. Mas se eu passasse numa banca seria a última coisa que eu leria. Se olhasse essa revista, se tivesse uma matéria de capa que 
me chamasse atenção, eu compraria na boa, mas seria a última coisa que eu leria. E, como isso vem embutido na revista, você já lê. Já pega um monte de conhecimento, eu acho que é de lambuja. [Lucas]

Os discursos de Lucas, Fernando e Rob nos permitem falar de aspectos que consideramos fundamentais neste trabalho: as ancoragens, as fronteiras com o feminino/homossexual e as possibilidades de flexibilização da masculinidade. A afirmação de Lucas de que o desconhecimento sobre esses assuntos e a procura por leituras que possam ajudar o homem a saber mais são pecados inconfessáveis para alguns homens, "os machistas", remete-nos aos discursos de Fernando e Rob. Nesse caso, a Men's Health seria a solução para os homens que desejam saber mais, mas são "impedidos" pelas normas de gênero. Ao trazer as matérias sobre sexualidade "misturadas" entre as que realmente devem fazer parte do elenco de interesses masculinos, como musculação e alimentação para aprimorar o corpo, possibilita que os homens tenham a oportunidade de ler, gostar e aprender com as matérias. Trata-se também de acreditar que uma revista masculina não deveria, a priori, trazer o sexo e a sexualidade da forma que a Men's Health traz, como uma pedagogia.

Lendo a entrevista, foi impossível não pensar também que, sendo as mulheres historicamente mais reprimidas sexualmente que os homens, são eles os que têm dificuldade em assumir o interesse pelos aprendizados sobre sexualidade, enquanto as mulheres há muito vêm sendo estimuladas, pelo menos pela mídia, a buscar esses conhecimentos. Seria contraditório se os homens não fossem percebidos como "naturalmente" mais aptos e sabedores de como fazer sexo, enquanto as mulheres têm que aprender para se tornarem aptas. Mas devem aprender lendo manuais e revistas, e não praticando, ou podem ser taxadas de "putas". Em contrapartida, as normas da masculinidade mais tradicional preconizam que a sexualidade é algo que os homens aprendem na vida, com a vivência, fazendo sexo, e não com manuais, como podem fazer as mulheres, como afirmou Lucas.

Podemos inferir então que esse cuidado masculino de negar a necessidade de aprendizado através de uma revista, presente nos discursos de Fernando, Lucas e Rob, é mais um lugar de reafirmação da masculinidade a partir da oposição ao que é feminino. A ideia que fica desses discursos é que há uma espécie de incompatibilidade entre os homens e essa abordagem da sexualidade. Homens fazem sexo e não discutem sobre sexo. 
Entretanto, os discursos dos homens mais jovens, leitores ou não da revista, vão de encontro a essas posições e são emblemáticos do primeiro modelo classificatório. Entre os que afirmam aprender com leituras e práticas, destacamos o discurso de Hélio (E) - 23 anos, solteiro, com nível superior, de classe média e não leitor, embora tenha apontado que lê eventualmente algumas edições que sua irmã, professora de Educação Fisica, compra -, que afirmou ter, com 15, 16 anos, recorrido à internet para saber sobre sexo. Destacamos igualmente o discurso do informante Anderson (E), 23 anos, solteiro, cursando o nível superior, pertencente às classes populares e não leitor, que afirmou ter tido sua primeira experiência sexual com 21 anos com uma namorada séria, trazendo um dado bastante interessante. Ele declara que leu "alguma coisa antes" de iniciar a vida sexual, revistas como Playboy e Nova,

[...] porque se eu não tivesse lido nada, se eu não soubesse de nada ia ser ruim saber como eu ia me relacionar com a minha parceira. Acho que tem que pensar nos dois lados, né? [Anderson]

Destaca-se, finalmente, o discurso de Edgar (E), 24 anos, solteiro, cursando o ensino superior, de classe média e não leitor, que está em um mesmo relacionamento há seis anos. Ele afirmou que vem aprendendo com sua parceira, mas que procurou se informar em sites sobre o tema.

Contudo, foram os leitores da revista que construíram discursos exemplares acerca dos ensinamentos sobre sexualidade. Wilian, Davi e Guto, heterossexuais, solteiros, com nível médio de escolaridade e com 26, 23 e 31 anos, respectivamente, entrevistados via MSN, fogem do perfil do leitor projetado da revista por seu grau de escolaridade e sua classe social, o que torna suas entrevistas bastante interessantes. A geração é uma variável importante neste trabalho, revelada, entre outras questões, na forma como esses homens se referem às matérias sobre sexualidade na revista, se compararmos seus discursos aos de homens mais velhos, também das classes trabalhadoras, citados anteriormente.

É possível dizer que esses informantes revelaram um alto grau de adesão com relação aos discursos da revista, ou seja, tomam essas "verdades" para construirem suas impressões sobre masculinidades, corpo, saúde e masculinidades, muitas vezes repetindo quase que literalmente o conteúdo de alguns editoriais ou fazendo clara menção a eles ou a matérias. Parecem se apropriar dos discursos da publicação para compor suas identidades masculinas, suas impressões sobre o mundo e sobre si mesmos, incorporando-os às próprias vidas. 
Assim como os demais, Davi, que estava namorando na ocasião, afirmou que as matérias sobre sexualidade não eram as que lia primeiro, mas acabou revelando que se beneficiava bastante delas:

Elas ensinam a você ter autoconfiança, a se cuidar melhor, como abordar uma garota numa balada, uns truques na arte da conquista, seus limites, posições na hora do sexo, o que deve e o que não deve fazer na hora $\mathrm{H}$... aprendi umas coisas bem legais. [Davi]

Depois dessa introdução, ele afirmou que estava se sentindo "um pouquinho cara-de-pau" por tocar nesse assunto com uma mulher, apesar de ser via internet. Apesar disso, retomamos a conversa, e ele reafirmou que aprendia muito com as matérias, trazendo temas interessantes: sexo oral, posiçôes de cama, saúde pra se manter firme na cama. Perguntado se esta "firmeza" significava ereção, respondeu que não era essa a questão, pois ainda era jovem, e o que buscava era saúde e possibilidade de "transar mais de uma vez, duas, três, quatro". Perguntamos em que a revista o tinha ajudado, e ele respondeu o seguinte:

A saber meu limite... respeitar o meu limite, os cuidados com a saúde, com as doenças, não pra ser o "bambambam" das noitadas... Você vê isso numa mesa de bar, numa balada tem aquele cara que quer aparecer... eu tenho os meus limites tanto físicos como psicológicos [...] Ela ensina a manter a calma... assim você dá prazer à garota, tudo na base do seu limite e no limite dela, respeitando uns aos outros. [Davi]

Como o informante já havia chamado nossa atenção para sua idade, durante um bom tempo achamos que ele se referia à ejaculação precoce ou ao controle da ejaculação precoce. Mas ele nos esclareceu: "Nunca gozei rápido. Eu demorava pra gozar e nunca pensava muito em mim". Ele falava então de algo mais sutil e que não dizia respeito somente à vivência da sexualidade, mas a aspectos que a revista trata de forma especial, sobretudo nos editoriais: autocontrole, autoconfiança, conhecimento sobre os próprios limites para melhor desenvolver a disciplina necessária para obtenção do sucesso em diversos setores da vida e confiança que lhe garanta a possibilidade de não se tornar um falastrão com relação ao sexo, mas um homem realmente "bom de cama". Controlar do corpo visando maximizar o desempenho sexual, tirar maior proveito do ato sexual, dar mais prazer a si e à parceira, tudo isso faz parte da pedagogia da sexualidade na revista. Nesse sentido, os discursos desse informante parecem saídos das páginas dos editoriais, tamanha a proximidade com aquelas "verdades".

É importante perceber que se trata de um sujeito muito novo, saído há pouco da adolescência, fase atravessada pela ideia de sexualidade "descontrolada", como 
afirma Olivarria (1999). Indo de encontro a tal ideia, Davi se constrói como controlado e disciplinado, propenso a dar prazer para a parceira, maximizando assim o seu próprio - marcas de maturidade e masculinidade presentes na revista. Ele ainda traz para experiência sexual o que a revista recomenda sobre o corpo: controle, disciplina e força de vontade para conseguir os objetivos estéticos. Dizemos isso porque consideramos que na revista a sexualidade é onde menos incide a ideia de controle no sentido, como informou Davi, sendo, justamente, uma válvula de escape da disciplina que a revista recomenda aos homens de modo geral.

O informante Wilian não tinha namorada no momento da entrevista, mas se relacionava sexualmente com uma moça, uma "ficante", como classificou. Em nossa conversa sobre aprendizados sexuais, ele afirmou o seguinte:

Wilian - Deixa eu ver...sobre sexo acho que como quebrar o tabu do sexo anal.

Pesquisadora - Acho que li uma matéria sobre isso há uns meses... ${ }^{10}$

W - Isso mesmo, coloquei em prática ontem depois de tanto tempo conversando...

P - Mas era uma coisa que você já vinha pensando em fazer ou foi a revista que te incentivou?

W - Não, era uma coisa que a minha ficante já tinha feito com o ex-namorado e ela não se sentiu bem, aí fiz todo um clima, conversei com ela um tempo sobre isso, que era normal (no sentido corriqueiro), que se ela sentia vontade da gente praticar, mas sem o trauma, sem pressão, ao natural. Acho que consegui entender melhor o que diz na revista e tentei colocar em prática.

P - Mas pra você era normal ou não?

W - Pra mim sexo anal não era normal. Ainda mais em cidade pequena e tal... E comigo também não era normal, mas não tinha preconceito não, acho que todos temos fantasias, mas não colocamos em prática por tabus ou preconceitos. Acho que colocarmos em prática é natural evolução do ser humano.

P - Aprendeu mais alguma coisa nessa área?

W - Jantares românticos... então o que eu faço? Guardo as revistas e tem coisa que se lê e depois não se lembra, então guardo. Por exemplo, se for sair com uma garota ou convidar ela pra jantar aqui, procuro buscar informaçōes. Acho que toda mulher gostaria de alguém que sabe cozinhar um prato novo, então enquanto não acho uma namorada eu vou aprendendo aqui e fazendo para a família. 
O discurso de Wilian explicita um aprendizado específico sobre sexualidade. E é interessante perceber que a revista não somente o ajudou a construir argumentos para convencer a "ficante" a fazer sexo anal, mas simplificou o tema para ele próprio, pois, como disse, para ele também essa prática "não era algo normal”, ou usual, sobretudo em sua cidade no interior no Rio Grande do Sul. É interessante também perceber que esse informante, que pertence às classes populares e mora com a família, adota um discurso bastante próximo ao da revista, que se dirige a um homem projetado das camadas médias, mais velho, independente e que mora sozinho. Isso nos revela que ele vem se apropriando de forma muito importante dos discursos da revista.

Ainda com relação à aprendizagem, o informante Guto, leitor que estava noivo, também afirmou que as matérias o ajudam, pois trazem

[...] dicas e macetes...algo que eu possa fazer diferente... Para fazer com que minha parceira fique mais fogosa... Alguma manha e algumas dicas de sedução também.... [Guto]

Guto afirma que os homens são egoístas sexualmente, e que também era assim antes de se apaixonar, mas que a revista o está ajudando a mudar esse quadro:

Tive um relacionamento de um ano onde eu não sabia o ponto G. Nesse outro de quase três anos já é totalmente diferente. Agora sempre faço minha parceira ter o orgasmo primeiro, controlo minha ejaculação... li isso na Men's Health. [Guto]

É interessante que Davi e Guto leem as matérias sobre sexualidade para agradar suas namoradas, mulheres com quem vivem uma relação estável. Mas é importante dizer que a ideia de prazer sexual do casal em uma relação fixa está mais presente nos discursos do editor e de alguns leitores do que propriamente na revista. Assim, os discursos desses dois informantes contrariam, por exemplo, o que afirmou Augusto, durante o grupo focal na empresa. Com 33 anos e casado, seu discurso se filia ao terceiro modelo classificatório. Esse informante argumentou que as matérias da revista eram mais apropriadas aos jovens que não viviam relações estáveis. Eles se beneficiariam com as "fórmulas" oferecidas pelas matérias, pois não teriam (por não querer) a oportunidade de ficar mais tempo com a mulher/parceira e conhecer os meandros do seu prazer. Em suas palavras:

Essas matérias seriam então para o pessoal mais novo, na faixa etária entre 18 e 15 anos, que têm uma vida sexual ativa com várias parceiras, digamos assim, mas nada muito profundo. Aquele famoso sexo casual, né? Você vai uma noite, faz sua parte lá e vai embora, mas ele não tem um envolvimento. Aí, faz uma coisa mecânica. Se você tem uma consultora que te diz exatamente o que vai fazê-la mais feliz naquele determinado momento de repente tiraria pouco do valor dessas matérias. 
O informante, no entanto, afirmou que dicas sobre como "incrementar" uma relação estável seriam bem-vindas. Uma ideia que vai ao encontro do que afirmaram Mauro (E) e Luiz (GF) sobre terem procurado informaçôes sobre sexo para melhorar a relação conjugal e agradar as esposas. Mauro procurou em algumas edições da própria Men's Health, enquanto Luiz lançou mão de sites.

Os discursos dos informantes, mesmo os de Lucas, Fernando e Rob, permitem- nos afirmar que havia um público para um tema que até pouco tempo não era muito explorado pela mídia masculina, e ao qual a Men's Health vem atendendo. Um público que vem se preocupando em agradar as mulheres, sejam namoradas, esposas ou ficantes. Revelam também que podemos eleger a geração como a variável mais importante para a assimilação de uma pedagogia da sexualidade via Men's Health e outras mídias, embora a assimilação de valores das classes médias seja relevante também. E também o desejo, ou necessidade, de associação à masculinidade tradicional, ainda dominante em nossa sociedade, ou sua flexibilização, como elementos importantes para a negação ou o engajamento nessas formas de aprendizado sobre sexualidade. Homens menos preocupados em demostrar sua masculinidade a partir da defesa da prática sexual como aprendizado exclusivo sobre como se faz (bom) sexo seriam possíveis leitores das matérias.

Por fim, ficou claro que por mais que o corpo da mulher esteja exposto e seja esmiuçado, reforçando a ideia do corpo feminino "para o outro" - como apontou Bourdieu (2003) - e misterioso e problemático - como vem sendo mostrado desde o século XIX (ROHDEN, 2001) -, os informantes não percebem esses aspectos como preconceituosos ou sexistas. Talvez porque o corpo feminino não esteja exposto como nas poses das revistas masculinas tradicionais. Quando perguntamos sobre se consideravam a revista machista de alguma forma, foram citadas justamente as matérias sobre sexualidade para justificar que a revista não era machista.

\section{Considerações finais}

Sobre a revista Men's Health, podemos dizer que ela vem se tornando um lugar de construção de novas verdades sobre as masculinidades no que diz respeito ao corpo, à saúde e à sexualidade. Com relação a esta, acreditamos que suas abordagens são, na maioria das vezes, essencializadas, têm efeito normativo e constroem a ideia de homogeneização da sexualidade feminina e masculina. No 
entanto, essas matérias apontam para o fato de que os conhecimentos sobre sexo e sexualidade podem, além de construídos nas práticas, ser também adquiridos através de manuais, como os que têm sido oferecidos às mulheres há décadas.

Apesar da maior liberdade sexual que os homens experimentam ainda hoje e da ideia comumente difundida de uma "aptidão natural" masculina para o sexo, o conhecimento sobre o ato sexual não é inato aos homens e precisa ser aprendido, ou pode ser aprimorado. Uma nova abordagem entre as revistas masculinas e que aproxima a Men's Health das muitas publicações femininas, e os homens, das mulheres. Como percebemos nos discursos de alguns informantes, isso pode causar estranhamento ou recusa por parte de muitos homens.

Com relação às mudanças no modelo de masculinidade, consideramos que o "homem da revista" e o "novo homem" construído pelos informantes não são os mesmos, uma vez que a publicação não contempla de forma importante mudanças mais profundas no modelo tradicional de masculinidade, investindo mais fortemente nas mudanças estéticas.

As variáveis geração e classe social foram as que claramente balizaram os discursos dos sujeitos, tendo sido fundamentais para a percepção dos informantes sobre essa pedagogia. Enquanto os mais jovens vêm apelando para essa possibilidade sem maiores problemas, os homens com mais de 40 anos não se sentem atraídos pela possibilidade de aprender ou aprimorar através de leituras a forma de fazer sexo. Foi interessante perceber que assumir esse tipo de aprendizado pode ser um problema para os homens mais alinhados ao modelo tradicional, independentemente da classe, da formação escolar e da idade. Parecenos que o problema nesses casos ainda é o medo da proximidade com o feminino em um aspecto tão caro aos homens: a prática sexual.

Percebemos que os entrevistados consideram um avanço as dicas $\mathrm{e}$ conhecimentos sobre a sexualidade, fisiologia e corpo feminino que as matérias trazem, considerando essa abordagem uma marca de modernidade da publicação. No entanto, não podemos esquecer que a ideia de proporcionar prazer à mulher foco principal dessa pedagogia e arrolada pelo editor como um aspecto moderno da revista - está atrelada à ideia de que o prazer proporcionado deve retornar ao homem de forma maximizada. Porém, ao que parece, os informantes não percebem ou não compartilham da lógica do editor sobre a maximização do próprio prazer ser o principal objetivo quando se proporciona mais prazer à mulher. 
Também podemos dizer que os aspectos inovadores presentes nessa pedagogia não vão além dessas práticas, não levando a reflexões sobre mudanças mais profundas com relação à sexualidade. A revista, por exemplo, silencia sobre a sexualidade homossexual, aspecto que foi reclamado por alguns informantes leitores homossexuais. Parece claro que o silenciamento absoluto sobre a homossexualidade é parte do empenho de negação da proximidade com esse público e a manutenção do espaço comercial da revista. A esse silenciamento se juntam a exposição do corpo feminino e a ênfase no sexo heterossexual. Mas toda essa ênfase no sexo heterossexual acaba por reforçar antigas crenças sobre a masculinidade, como, por exemplo, a supervalorização do sexo e da boa performance sexual e a ideia de desejo sexual constante.

Por fim, ficou claro que os depoimentos dos leitores revelaram uma grande assimilação dos discursos da revista, demonstrando que eles vêm se apropriando de forma importante desses discursos para comporem suas percepções sobre sexualidade e masculinidades. E que, apesar das afirmaçôes do seu editor sobre a revista velar pelas mudanças na masculinidade tradicional, a Men's Health pode ser considerada uma aliada mais importante da sociedade de consumo do que dos movimentos sociais que vêm questionando posições masculinas com relação às mulheres e aos outros homens. ${ }^{11}$

\section{Referências}

ALMEIDA, M.V. de. Senhores de Si. Uma interpretação antropológica da masculinidade. 2a ed. Lisboa: Fim de Século, 2000.

BADINTER, E. XY: de l'identité masculine. Paris: O. Jacob, 2010.

BOURDIEU, P. A dominação masculina. 3a ed. Rio de Janeiro: Bertrand Brasil, 2003.

CONNELL, R.W. Globalization, imperialism, and masculinities. In: KIMMEL, M.; HEARN, J.; CONNELL, R.W. (ed.). Handbook of studies on men \& masculinities. California: Sage, 2005. p. 71-90.

; HEARN, J.; KIMMEL, M.S. Introduction. In: KIMMEL, M., HEARN, J.,

CONNELL, R.W. (Ed.). Handbook of studies on men \& masculinities. USA: Sage, 2005.

CONNELL, R.W. La organización social de la masculinidad. In: VALDÉZ, T.; OLIVARRÍA, J. (Ed.). Masculinidadles: poder y crisis. Santiago: FLACSO, 1997. p. 31-48. . Políticas da masculinidade. Revista Educação e Realidade. Porto Alegre, v.20, n.2, jul/dez, p. 185-206, 1995. 
FOUCAULT, M. A arqueologia do saber. 7.ed. Rio de Janeiro: Forense Universitária, 2007.

. História da Sexualidade I: a vontade de saber. Rio de Janeiro: Graal, 1997.

. História da Sexualidade II: o uso dos prazeres. Rio de Janeiro: Graal, 1985.

. Poder -Corpo. In: Microfísica do poder. Rio de Janeiro: Graal, 1993.

FRASER, M.T.D.; GONDIM, S.G. Da fala do outro ao texto negociado: discussóes sobre a entrevista na pesquisa qualitativa. Revista Paideia, v. 14,n. 28, p. 139-152, 2004.

GUTMAN, M.C.; VIGOYA, M.V. Masculinities in Latin America. In: KIMMEL, M.; HEARN, J.; CONNELL, R.W. (Ed.). Handbook of studies on men \& masculinities. California: Sage, 2005.

HEILBORN, M.L.; CARRARA, S. Em cena, os homens. Revista Estudos Feministas. Ano 6, 2 sem., p. 370-374, 1998.

. Entre as tramas da sexualidade brasileira. Revista Estudos Feministas, Florianópolis, v.14, n.1, p.336, jan./abr., p. 43-59, 2006.

; GOUVEIA, P.F. "Marido é tudo igual"- mulheres populares e sexualidade no contexto da Aids. In: PARKER, R.; BARBOSA, R. Sexualidades pelo avesso. Direitos, identidades e poder. São Paulo: Ed. 34, 1999. p.175-198.

KIMMEL, M. Homofobia, temor, vergüenza y silencio en la identidad masculina. In: VALDÉS, T.; OLIVARRIA, J. (Ed.). Masculinidade/s - poder y crisis - Chile: FRACSO, n. 24, p.49-62, 1997.

. A produção simultânea de masculinidades hegemônicas e subalternas. Horizontes Antropológicos - Corpo, doença e saúde, Publicação do programa de pós-graduação em antropologia social da Universidade Federal do Rio Grande do Sul, n.9, p.103-117, 1998.

; KAUFMAN, M. Weekend Warriors: the new men's movement. In: (Ed.).

The politics of manhood. Profeminist men respond to the mythopoetic men's movement (and the mythopoetic leaders answer). Philadelphia: Temple, 1995.

LERVOLINO, S.A.; PELICIONI, M.C.F. A utilização do grupo focal como metodologia qualitativa na promoção da saúde. Revista da Escola de Enfermagem da USP, v. 35, n. 2, p. 115-121, 2001.

MINAYO, M.C. O desafio do conhecimento: pesquisa qualitativa em saúde. 6. ed. São Paulo: Hucitec, 1999.

OLIVARRIA, J. Desejos, prazeres e poder: questôes em torno da masculinidade heterossexual. In: PARKER, R.; BARBOSA, R. (Org.). Sexualidades pelo avesso. Direitos, identidades e poder. São Paulo: Ed. 34, 1999.

NIXON, S. Hard looks. Masculinities, spectatorship and contemporary consumption. London: Routledge, 2003. 
NOLASCO, S.A .O mito da masculinidade, Rio de Janeiro:Rocco, 1993.

PINTO, M.J. Comunicação e discurso: introdução à análise do discurso. 2a ed. São Paulo:Hacker, 2002.

RAMOS, J. de S. Dilemas da masculinidade em comunidades de leitores da revista Men's Health. Sexualidad, Saludy Sociedad - Revista Latinoamericana. n.7, p.9-43, abr 2011.

ROHDEN, F. Uma ciência da diferença: sexo e gênero na medicina da mulher. Rio de Janeiro: Fiocruz, 2001 (Coleção Antropologia e Saúde).

SCOTT, J. Gênero: uma categoria útil de análise histórica. Educação e Realidade, v.20 n.2, jul/dez, 1995.

WEEKS, J. O corpo e a sexualidade. In: LOURO, G.L. (Org). O corpo educado. Pedagogias da sexualidade. Belo horizonte: Autêntica, 1999.

\section{Notas}

${ }^{1}$ Este artigo é fruto da tese de doutorado intitulada Sexualidade, corpo e saúde masculinos: transformaçôes e permanências nos discursos de homens e da revista Men's Health, defendida em maio de 2011 no Instituto de Medicina Social da UERJ.

${ }^{2}$ As entrevistas foram realizadas pelo MSN e chegamos a esses informantes através de comunidade sobre a revista no site de relacionamento Orkut. Lançamos mão dessa estratégia devido à dificuldade de encontrar homens leitores da revista através da rede de relações pessoais.

${ }^{3}$ O Projeto foi aprovado pelo Comitê de Ética do Instituto de Medicina Social (IMS-UERJ). Os entrevistados via MSN receberam o termo e confirmaram sua aceitação.

${ }^{4}$ Ao falar de classe social tomamos como referência a ordem simbólica, ou ethos de classe, mas também o nível de renda associado ao grau de escolaridade, aspectos distintos acerca dessa variável, mas presentes nos discursos dos informantes e da revista.

${ }^{5}$ Elegemos as ediçôes de 2009 como principais na análise por ser esse o ano de realização das entrevistas e dos grupos focais, quando muitas dessas edições foram utilizadas como deflagradoras de discursos durante esses eventos. Ampliamos o período para análise dos editorias por considerar que os textos eram muito relevantes para a pesquisa. Editoriais de 2008: janeiro, fevereiro, abril, maio, junho, setembro, outubro e novembro, de 2009: janeiro, fevereiro, março, maio, junho, agosto, setembro e outubro. Disponíveis em http://menshealth.abril.com.br.

${ }^{6}$ Todos os artigos de Raewyn Connell citados neste trabalho foram assinados com o nome Robert Connell, por isso estarão assim nas referências bibliográficas.

${ }^{7}$ O termo "metrossexual" foi utilizado pela primeira vez em 1994 em um jornal britânico como referência aos homens ingleses, urbanos e heterossexuais que tinham preocupações especiais com a estética. Percebemos que entre os informantes mais tradicionais, esse modelo é tomado como pejorativo devido à relação estabelecida entre vaidade e feminilidade/homossexualidade.

${ }^{8}$ Tomamos o termo "machismo" como um sistema tradicional que tem o sexismo como aspecto central e como práticas masculinas bastante presentes na América Latina (GUTMAN; VIGOYA, 2005). 
9 A categoria "masculinidade tradicional" é tomada como contraposição à "nova masculinidade" ou "novo homem". Trata-se de uma referência feita por Connell (1995) acerca da masculinidade relacionada à família tradicional, produzida no mundo moderno e atrelada à ideia de permanência e não de transitoriedade, como é próprio do gênero.

${ }^{10} \mathrm{O}$ leitor refere-se à matéria: "Último tabu.... está aberto para discussão! A chave para você falar de sexo anal com sua garota está aqui: veja exatamente o que e como fazer para convencê-la a ter uma experiência inesquecível", de setembro de 2009.

${ }^{11}$ C.R. Ribeiro realizou a leitura crítica da revista Men's Health, as entrevistas e os grupos focais, e analisou dos dados construídos nesses eventos, utilizados na escrita desse artigo. J.A. Russo orientou a tese que originou o artigo, colaborou na análise dos dados da pesquisa e na escrita do artigo. F. Rohden co-orientou a tese que originou o artigo, colaborou na análise dos dados construídos durante a pesquisa e na readação do artigo. 
A new pedagogy of sexuality for men: media discourse and its reverberations

This paper, guided by the concepts of gender, masculinity and sexuality, analyzes the speeches of men and Men's Health magazine about learning on sexuality. We analyzed the editorial of the magazine issues in 2008 and 2009, 2009 editions, and speeches of men during interviews and focus groups. We conclude that the magazine presents the idea of a new pedagogy of sexuality for men, something new in publications for men, and, concerning the informants, the variables social class, generation and adherence to the dominant model of masculinity have considerable influence on their learning about sexuality and acceptance of this pedagogy in the magazine.

$>$ Key words: gender; masculinity; pedagogy of sexuality; Men's Health magazine. 